\title{
How different characterization techniques elucidate the nature of the gold species
}

\section{in a polycrystalline $\mathrm{Au} / \mathrm{TiO}_{2}$ catalyst}

Wolfgang Grünert ${ }^{\mathrm{a} *}$, Dennis Großmann ${ }^{\mathrm{a}}$, Heshmat Noei ${ }^{\mathrm{a}, \mathrm{b}}$, Marga-Martina Pohl ${ }^{\mathrm{c}}$, Ilya Sinev ${ }^{\mathrm{a}}$, Andrea De Toni ${ }^{\mathrm{a}, \mathrm{d}}$, Yuemin Wang ${ }^{\mathrm{a}, \mathrm{e}}$, and Martin Muhler ${ }^{\mathrm{a}}$

Dedicated to Prof. Manfred Baerns on the occasion of his $80^{\text {th }}$ birthday

- Prof. Wolfgang Grünert, (a) Lehrstuhl Technische Chemie, Ruhr-Universität Bochum, P.O. Box 102148, 44780 Bochum, Tel. +49 234322 2088, Fax +49 234321 4115, w.gruenert@ techem.rub.de

- Dr. Dennis Großmann, (a) Lehrstuhl Technische Chemie, Ruhr-Universität Bochum, P.O. Box 102148, 44780 Bochum, Tel. +49 234322 7693, Fax +49 234321 4115, dennis@ techem.rub.de

- Dr. Heshmat Noei, (b) Desy, Notkestraße 85, 22607 Hamburg, Tel. 040 89986011, heshmat.noei@desy.de

- Dr. Marga-Martina Pohl, (c) Leibniz-Institut für Katalyse e.V. at Rostock University, Albert-EinsteinStraße 29a, 18059 Rostock, Tel. +49 3811281 306, Fax +49 3811281 51306, Marga-

Martina.Pohl@catalysis.de

- Dr. Ilya Sinev, Lehrstuhl Technische Chemie, Ruhr-Universität Bochum, P.O. Box 102148, 44780 Bochum, Tel. +49 234322 4818, Fax +49 234321 4115, iljas@ techem.rub.de

- Dr. Andrea De Toni, (d) IAV Entwicklungszentrum, Nordhoffstraße 5, 38518 Gifhorn, Tel. via +49 5371 805-0, Fax +49 5371 805-1250, com.star@gmx.de

- Dr. Yuemin Wang, (e) Physikalische Chemie I, Ruhr-Universität Bochum, P.O. Box 102148, 44780 Bochum, Tel. +49 234322 4217, Fax +49 234321 4182, wang@pc.rub.de

- Prof. Martin Muhler, (a) Lehrstuhl Technische Chemie, Ruhr-Universität Bochum, P.O. Box 102148, 44780 Bochum, Tel. +49 234322 8754, Fax +49 234321 4115, muhler@techem.rub.de 


\section{Abstract}

$\mathrm{TiO}_{2}$-supported gold species were prepared via the deposition-precipitation route, with conservation of the initial speciation by freeze-drying. The structural and electronic properties of the Au species were investigated by X-ray absorption spectroscopy, electron microscopy, and IR spectroscopy of adsorbed CO in four states: after freeze-drying, after use in catalysis of $\mathrm{CO}$ oxidation at $\mathrm{T} \leq 303 \mathrm{~K}$, and after thermal treatments at $623 \mathrm{~K}$ in $\mathrm{He}$ and in (synthetic) air. Exclusively $\mathrm{Au}^{\mathrm{III}}$ was deposited on the $\mathrm{TiO}_{2}$ surface in patches ranging from isolated $\mathrm{Au}$ ions to three-dimensional clusters. Au-Au scattering was not observed in EXAFS despite the aggregation, presumably due to pronounced disorder. In this state, Au was hardly detected by adsorbed IR spectroscopy of CO, probably due to site blockage by residual water molecules. After $\mathrm{CO}$ oxidation $\left(\mathrm{T} \leq 303 \mathrm{~K}\right.$ ), only a minority of $\mathrm{Au}^{\mathrm{III}}$ species was reduced to $\mathrm{Au}^{0}$, forming neutral and positively charged clusters $\left(\mathrm{Au}_{\mathrm{n}}{ }^{0}, \mathrm{Au}_{\mathrm{n}}{ }^{\delta+}\right)$ as described in literature. In HAADFSTEM the material appeared unchanged except for few bulk metal particles. Thermal treatment in $\mathrm{He}$ at $623 \mathrm{~K}$ resulted in complete reduction of $\mathrm{Au}{ }^{\mathrm{III}}$ to coexisting $\mathrm{Au}_{\mathrm{n}}{ }^{0}$ and $\mathrm{Au}_{\mathrm{n}}{ }^{\delta+}$. In this state, microscopy revealed the survival of plenty of disordered structures, even single atoms, coexisting with 1-2 nm particles and few large crystallites. Calcination in air at $623 \mathrm{~K}$ almost completely eliminated the $\mathrm{Au}_{\mathrm{n}}{ }^{\delta+}$ state and the disordered material, resulting in welldispersed three-dimensional $\mathrm{Au}$ metal nanoparticles on the $\mathrm{TiO}_{2}$ surface. The unique contributions of all characterization techniques to this structural model are illustrated in detail.

Keywords: Gold catalysts, $\mathrm{TiO}_{2}$, structural characterization, XAFS, Electron microscopy, IR spectroscopy, CO adsorption 


\section{Kurzfassung}

Goldspezies auf Titandioxid wurden durch das „Deposition-Precipitation“-Verfahren hergestellt und die anfängliche Speziesstruktur durch Gefriertrocknen konserviert. Die Eigenschaften der Goldspezies wurden durch Röntgen-Absorptionsspektroskopie, Elektronenmikroskopie und IR-Spektroskopie an adsorbiertem CO in vier Zuständen untersucht: Nach dem Gefriertrocknen, nach der katalytischen $\mathrm{CO}-$ Oxidation bei $\mathrm{T} \leq 303 \mathrm{~K}$ sowie nach thermischen Behandlungen in He bzw. in (synthetischer) Luft bei $623 \mathrm{~K}$. Gold wurde ausschließlich als $\mathrm{Au}^{\mathrm{III}}$ auf der $\mathrm{TiO}_{2}$-Oberfläche deponiert, in Anordnungen, die vom Einzelion bis zu dreidimensionalen Clustern reichten. Im EXAFS war der Au-Au-Streupfad trotz der Aggregation nicht vorhanden, offenbar wegen ausgeprägter Unordnung. In diesem Zustand war Gold durch CO-Adsorption im IR fast nicht nachweisbar, wahrscheinlich weil seine Koordinationsstellen von verbliebenen Wassermolekülen blockiert waren. Nach CO-Oxidation bei $\mathrm{T} \leq 303 \mathrm{~K}$ war nur ein kleiner Teil des Goldes $\mathrm{zu} \mathrm{Au}^{0}$ reduziert und trat in den in der Literatur beschriebenen neutralen oder schwach positiv geladenen Clustern $\left(\mathrm{Au}_{\mathrm{n}}{ }^{0}, \mathrm{Au}_{\mathrm{n}}{ }^{\delta+}\right)$ auf. HAADF-STEM zeigte außer gelegentlichen massiven Goldkristalliten wenig Unterschiede zur Ausgangsprobe. Durch thermische Behandlung in He bei $623 \mathrm{~K}$ wurde das Gold komplett $\mathrm{zu} \mathrm{Au}^{0}$ (wiederum als $\mathrm{Au}_{\mathrm{n}}{ }^{0}$ und $\mathrm{Au}_{\mathrm{n}}{ }^{\delta+}$ ) reduziert. Auch in diesem Zustand detektierte HAADF-STEM neben 1-2 nm großen Partikeln und wenigen größeren Kristalliten vielerorts ungeordnete Goldspezies bis hin zu Einzelatomen. Kalzination in Luft bei $623 \mathrm{~K}$ beseitigte sowohl den $\mathrm{Au}_{\mathrm{n}}{ }^{8+}$-Zustand also auch die ungeordneten Spezies fast völlig und resultierte in feinverteilten metallischen Gold-Nanopartikeln auf der $\mathrm{TiO}_{2}$-Oberfläche. Die spezifischen Beiträge der Charakterisierungstechniken zur Aufklärung der Speziesstruktur werden im Detail diskutiert.

Schlagwörter: Gold-Katalysatoren, $\mathrm{TiO}_{2}$, Strukturanalyse, XAFS, Elektronenmikroskopie, IR-Spektroskopie, CO-Adsorption 


\section{Introduction}

Development and optimization of heterogeneous catalysts can nowadays rely on different strategies and combinations thereof - the recent high-througput experimentation approach may serve to scan wider parameter fields, while the traditional knowledge-based approach remains important to make the best from given systems or to identify new problems or parameters. The holy grail of knowledge-based catalyst development is the full understanding of a real catalyst, which includes the identification of the active sites for the reactions possible in the reaction environment, of methods to produce and manipulate them, the knowledge of the molecular reaction mechanisms proceeding on the active sites, and the kinetic modeling of these mechanisms (microkinetic models). The considerable progress made in this respect for some simple but important reactions such as ammonia synthesis over Fe or Ru catalysts [1-3] or methanol synthesis over $\mathrm{Cu} / \mathrm{ZnO} / \mathrm{Al}_{2} \mathrm{O}_{3}$ catalysts [4-6] has been made possible by joint efforts of surface scientists, theoreticians, and catalysis experts. The crucial step in such cooperation is to bridge the gaps between model situations treated in surface science and theory and the extremely complex situation in real catalysis. For this, models have to be complicated and real catalysts must be simplified without losing characteristic features of the catalytic behavior, and the reaction atmospheres have to be converged starting from such diverse conditions as ultrahigh vacuum (surface science) and zero $\mathrm{K}$ (theory), and tens of bar and hundreds of $\mathrm{K}$ in real catalysis.

The complexity of most real catalysts even in simplified versions is an everlasting challenge to any effort for their structural characterization and for correlating structural with reactivity properties. In recent years, valuable insight into the role of catalyst components in the catalytic process has been achieved by spectroscopic measurements of the working catalysts under conditions where meaningful rate measurements were performed simultaneously ("in operando") [7]. As a consequence, almost all characterization techniques including even those requiring ultrahigh vacuum (e.g. XPS) have meanwhile been developed to a state where they 
can be applied in operando. In many cases, however, operando spectroscopy provides superimposed information consisting of contributions from both active sites and inactive surface species (spectators), which calls for additional, usually transient experiments to discriminate between them. The diagnostic potential of several techniques depends significantly on the measurement temperatures, which may limit their value in operando situations. This tends to aggravate a dilemma which is inherent to any effort of catalyst characterization, despite the sometimes stunning technical advances made in individual methods, e.g. electron microscopy: all techniques are principally limited in the scope of accessible information, none of them can give a full picture of a system as complex as a heterogeneous catalyst. This calls for the multitechnique strategies, which are nowadays familiar in catalyst characterization.

In the following, we present an illustrative example for a multitechnique (ex-situ) study of a titania-supported gold catalyst, which has been investigated in four different states. The data originate from a study in which a combination of catalytic with (ex-situ) characterization data allowed us showing that supported Au metal nanoparticles are not the only active site catalyzing low-temperature $\mathrm{CO}$ oxidation: rather, this reaction proceeds on $\mathrm{Au}^{3+}$ sites as well. While these results have been presented elsewhere with only a brief account for the problems of catalyst characterization [8], we use this example here to illustrate how a reasonably reliable structural model of this rather simple $\mathrm{Au} / \mathrm{TiO}_{2}$ catalyst can be only obtained by combining three traditional techniques applied on a state-of-the-art level and under optimum conditions: X-ray absorption spectroscopy (XAFS), electron microscopy, and IR spectroscopy of adsorbed CO molecules. It will be shown how the final conclusions depend on unique contributions of each method and how misinterpretation would have resulted from disregarding any of them. 


\section{Samples and methods}

Sample preparation has been described in detail in ref. [8]. In brief, 4 wt- $\%$ Au was deposited on $\mathrm{TiO}_{2}$ (Evonik P25) by the traditional deposition-precipitation technique, where $\mathrm{HAuCl}_{4}$ is initially neutralized and hydrolyzed before the support is added and the solvent water is gradually removed (here by filtration and freeze-drying). The catalyst was used without any further treatment. In particular, calcination which is known to produce Au nanoparticles was not performed. Characterization data presented below arise from the following states: "ini" as made, after freeze drying; "COox" - after use for CO oxidation starting with a contact of the catalyst with feed $\left(1 \% \mathrm{CO}, 20 \% \mathrm{O}_{2}\right.$, balance $\left.\mathrm{He}, 315000 \mathrm{ml} \mathrm{g}^{-1} \mathrm{~s}^{-1}\right)$ at room temperature followed by two temperature-programmed reaction runs between $220 \mathrm{~K}$ and room temperature; "He_623K" - after treating the catalyst in He at $623 \mathrm{~K}$ for $1 \mathrm{~h}$; “Air_623 K" - after treating the catalyst in synthetic air at $623 \mathrm{~K}$, following the He_623 K procedure.

XAFS at the AuL $L_{I I}$-edge (11918 eV) was measured at HASYLAB (Hamburg, Germany, X1 beamline, fluorescence mode) and at Alba (Barcelona, Spain, CLÆSS beamline, transmission mode). Higher harmonics in the X-ray beam was excluded by either detuning the monochromator to $50 \%$ of maximum beam intensity (X1) or by using a Pt-coated toroid mirror (CLÆSS). Spectra were measured at liquid nitrogen temperature (X1) to suppress thermal disorder or at room temperature (CLÆSS) with self-supporting pellets wrapped in Kapton tape. Analysis of the EXAFS spectra was performed with the software VIPER for Windows [9]. With the near-edge (XANES) region, Principal Component and Target Transformation Analysis were performed using XANDA for Windows [9]. Spectra of the initial sample and the one after "He_623K" were employed as references for the "COox" state. The component contributions extracted from the XANES were used to reproduce the measured EXAFS spectra by linear combination of the (experimental) component spectra.

UHV-FTIR was measured with a novel ultrahigh vacuum (UHV, base pressure $-2 \times 10^{-10}$ mbar) apparatus described elsewhere [10]. The $\mathrm{Au} / \mathrm{TiO}_{2}$ samples were first pressed on a gold- 
plated stainless steel grid and then mounted on a sample holder specially designed for FTIR transmission measurements under UHV and allowing for rapid heating and cooling of samples between 100 and $1000 \mathrm{~K}$. Prior to each exposure, a spectrum of clean samples was used as a background reference. All UHV-FTIR spectra were collected with 1024 scans at a resolution of $2 \mathrm{~cm}^{-1}$.

TEM images were recorded with an aberration-corrected JEM-ARM200F microscope (JEOL, Corrector: CEOS) at $200 \mathrm{kV}$ acceleration voltage. Aberration corrected STEM imaging High-Angle Annular Dark Field (HAADF) and Annular Bright Field (ABF) - was made with a spot size of approximately $0.13 \mathrm{~nm}$, a convergence angle of $30-36^{\circ}$ and collection semi-angles for HAADF and ABF of 90-170 mrad and 11-22 mrad, respectively. Samples were deposited without any pretreatement on a holey carbon supported Cu-grid (mesh 300) and transferred to the microscope.

For more experimental details the reader is referred to ref. [8].

\section{Results and discussion}

The XAFS signature of the initial catalyst is reported in Figure 1. From comparison with $\mathrm{HAuCl}_{4}$, a reference for $\mathrm{Au}(\mathrm{III})$, the XANES (Fig. 1a) shows the gold to be completely in the +3 oxidation state as expected. In the EXAFS (Fig. 1b), no significant shell beyond the nearest Au-O coordination can be seen. This is usually interpreted as indicating the gold species to be atomically dispersed. Actually, however, it shows just that there is no order beyond the first coordination sphere. It excludes ordered Au oxide or hydroxide particles and also metallic particles, which had been detected as a byproduct when the deposition-preparation technique was used under other circumstances [11].

In Figure 2a, the IR spectrum of $\mathrm{CO}$ adsorbed on this sample at $90 \mathrm{~K}$ is shown (spectrum a). The weak signal at $2179 \mathrm{~cm}^{-1}$ arises from CO adsorbed on $\mathrm{Ti}^{4+}$ sites [12-15]. While XAFS clearly detected $\mathrm{Au}^{3+}$ ions, there appears to be no indication for such state in the IR spectrum. 
Only after a temperature increase to $110 \mathrm{~K}$, which causes $\mathrm{CO}$ to desorb from $\mathrm{Ti}^{4+}$, the tailing of the disappearing signal turns out to contain a very small signal at $\approx 2160 \mathrm{~cm}^{-1}$ (spectrum a') arising from $\mathrm{CO}$ adsorbed on $\mathrm{Au}^{3+}[16]$. The ratio between the $\mathrm{Ti}^{4+}$ and $\mathrm{Au}^{3+}$ sites detected remains unknown due to lacking knowledge of extinction coefficients. The low intensity of the $\mathrm{Au}^{3+}$-related signal suggests that $\mathrm{Au}$ sites are still covered by remnants from the preparation process, probably water still being adsorbed after freeze drying. The sample was therefore briefly flashed to $500 \mathrm{~K}$ in vacuum. Spectrum $\mathrm{a}_{500}$ obtained after repeated adsorption of $\mathrm{CO}$ is indeed completely different: there are now also intense signals at $2162 \mathrm{~cm}^{-1}$ and 2108 $\mathrm{cm}^{-1}$. The latter is assigned to $\mathrm{CO}$ adsorbed at the rim sites between neutral $\mathrm{Au}^{0}$ clusters $\left(\mathrm{Au}_{\mathrm{n}}{ }^{0}\right)$ and $\mathrm{TiO}_{2}[12,13]$. The significant intensity between these signals turns out to result from an additional species (positively charged metal clusters, $\mathrm{Au}_{\mathrm{n}}{ }^{\delta+}[14]$ ): after desorption of $\mathrm{CO}$ from $\mathrm{Au}_{\mathrm{n}}{ }^{0}$ at $155 \mathrm{~K}$ its signal is visible as a shoulder at the slightly shifted $\mathrm{CO} / \mathrm{Au}^{3+}$ band at $2158 \mathrm{~cm}^{-1}$ band (spectrum $\left.\mathrm{a}_{500}{ }^{\prime}\right)$. Only relation to the XAFS results shows, however, that the sample has been changed by the treatment, because there was no $\mathrm{Au}^{0}$ in the initial state. Still, the experiment was valuable in proving the existence of adsorbates on most of the initial $\mathrm{Au}^{3+}$ sites.

The morphology of the Au species in the initial catalyst was disclosed by electron microscopy, in particular STEM. The images in Figure 3, row A show clearly that gold is not atomically dispersed although single atoms (ions) are indeed present (see encircled spots). More typical are, however, clusters with a disordered arrangement of the Au species. The clusters, which can be very different in size, seem to be rather two-dimensional patches on the $\mathrm{TiO}_{2}$ surface. However, where they can be visualized from the side, it can be seen that many of them extend into the third dimension (Fig. 3 A1). Although electron microscopy will never completely escape the objection to analyze only small samples out of very large populations, these images show conclusively that the absence of higher shells in the Au $L_{I I I}$ EXAFS (Fig. $1 \mathrm{~b})$ is due to disorder rather than to site isolation. On the other hand, XAFS was the only 
technique proving the absence of $\mathrm{Au}^{0}$ in this sample. One might argue that zero-valent gold should be detected in STEM by its tendency to form ordered particles, but it will be shown below that this is not necessarily the case.

The spectral signatures obtained after using the catalyst for $\mathrm{CO}$ oxidation at temperatures $\leq 303 \mathrm{~K}$ are reported in Figures 1 and 2, and typical STEM images are shown in Figure 3, row B. A linear combination analysis of the XANES (Fig. 1a) showed that $87 \%$ of the gold was still in the +3 oxidation state, i.e., the catalysts achieved their very high activities [8] with only a minority of $\mathrm{Au}$ species reduced to the metallic state. This was surprising because in catalysts prepared with a different kind of $\mathrm{TiO}_{2}$ support via the same deposition-precipitation route, gold had been completely reduced under these conditions [11]. However, because all possible experimental artifacts (storage, exposure to light or X-rays) would rather increase than decrease the Au reduction degree, there can be no doubt about the reliability of this result. In the EXAFS, the Au-Au shell indicative of metallic gold (2.75 $\AA$, uncorrected) was hardly discernible (Fig. 1b), which suggests a very small size of the gold particles. Indeed, the spectrum can be nicely reproduced by superimposing the initial spectrum with the one obtained after He_623K, which arises from small particles (see below), in the 87/13 ratio.

The IR spectrum of adsorbed CO (Fig. 2b, spectrum b) now contains most features already identified after heating the initial sample: There is $\mathrm{CO}$ adsorbed on (the rims of) neutral $\mathrm{Au}$ clusters $\left(\sim 2107 \mathrm{~cm}^{-1}\right)$, on $\mathrm{Au}_{\mathrm{n}}{ }^{\delta+}$ clusters $\left(2127 \mathrm{~cm}^{-1}\right)$, and on $\mathrm{Ti}^{4+}$ sites $\left(2179 \mathrm{~cm}^{-1}\right)$. Again, the $\mathrm{CO} / \mathrm{Au}^{3+}$ band $\left(2158 \mathrm{~cm}^{-1}\right)$ becomes clearly visible only after partial desorption of the $\mathrm{CO}$ from $\mathrm{Au}^{0}$-related sites, e.g. at $170 \mathrm{~K}$ (spectrum b'). Seeing these spectra, it is useful to call in mind the EXAFS evidence that the reduction degree of $\mathrm{Au}^{3+}$ to $\mathrm{Au}^{0}$ is just on the order of 15 $\%$. Obviously, the extinction coefficients of $\mathrm{CO}$ on $\mathrm{Au}^{0}$-related sites are very large. Therefore these bands dominate the spectrum even though arising from minority species. The STEM images confirm the XAFS results, because for most of the regions shown the texture of the 
gold phase is not much different from that of the initial catalyst. At some places, massive, obviously metallic gold particles of up to $10 \mathrm{~nm}$ size are visible (Fig. $3 \mathrm{~B} 1$ ).

After the thermal treatment in He at $623 \mathrm{~K}$, the XAFS results clearly show the complete reduction of gold. While the disappearance of the white line in the XANES (Fig. 1a) is no unambiguous proof for complete reduction $\left(\mathrm{Au}^{+}\right.$has a weak white line as well), the conclusion is supported by the EXAFS (Fig. 1b) where the Au-O coordination, which is typical of cationic gold, is completely gone. Still, the metallic Au-Au coordination is very small in the EXAFS, and the model fit resulted in a coordination number (C.N.) of 8 [8]. With a spherical particle model, a particle size of 1.2-1.3 nm can be estimated from such $\mathrm{C}$. N. according to a method described in ref. [17]. However, at such sizes, particles are most likely not spherical. Moreover, EXAFS probably somewhat underestimates sizes of small supported particles, because the support introduces some static disorder near the interface, which is difficult to handle in ordinary model fits and tends to decrease the resulting C. N.

The IR spectra of CO adsorbed after He_623K (Fig. 2b) confirm the conclusions with respect to the reduction degree of gold after this treatment. At $90 \mathrm{~K}$, only signals of $\mathrm{CO}$ on neutral $\left(\sim 2107 \mathrm{~cm}^{-1}\right)$ and positively charged Au clusters $\left(2127 \mathrm{~cm}^{-1}\right)$ and on $\mathrm{Ti}^{4+}\left(2179 \mathrm{~cm}^{-1}\right)$ appear (spectrum c). At $130 \mathrm{~K}$, where $\mathrm{CO}$ has been desorbed from $\mathrm{Ti}^{4+}$ (cf. Fig. 2a), the region around $2160 \mathrm{~cm}^{-1}$ is now completely flat (spectrum c') although $\mathrm{CO} / \mathrm{Au}^{3+}$ survives much higher temperatures if present (spectrum $\mathrm{a}_{500}$ '). With respect to $\mathrm{Au}^{0}$, the shoulder at $2127 \mathrm{~cm}^{-1}$ indicating $\mathrm{Au}_{\mathrm{n}}{ }^{\delta+}$ clusters is now much more intense than after COox. Despite their increased abundance there is no feature in the XAFS which would allow detecting these slightly charged clusters.

Figure 3, row $\mathrm{C}$ presents electron microscopic images of this state. The one in Fig. $3 \mathrm{C} 1$ tends to nicely agree with the EXAFS result: there are a multitude of particles in the $1 \mathrm{~nm}$ range as predicted. A TEM image of the same sample shown in [8] shows particles of $2 \mathrm{~nm}$ rather than of $1 \mathrm{~nm}$ size. The remaining two STEM images in Fig. $3 \mathrm{C}$ and other micrographs in [8] 
prove, however, that the actual situation is more complex: in between the aggregates, some of which are clearly larger than $2 \mathrm{~nm}$ (not shown), there are still disordered species, even occasionally individual atoms. Although the abundance of these structures is smaller than in the states discussed so far, they are by no means atypical. Unfortunately, the quantity of this disordered material is difficult to assess. One cannot strictly rule out that it is small enough to represent unconverted $\mathrm{Au}^{3+}$ having escaped observation by XAFS and IR spectroscopy due to detection limits. We consider this unlikely and rather tend to assign it to $\mathrm{Au}^{0}$ that has failed to join the next particles due to diffusion barriers existing on the polycrystalline anatase surface. The EXAFS spectrum after Air_623K was recorded at a different station where the state after He_623K was re-measured for reference (at room temperature instead of $77 \mathrm{~K}$ ). Both spectra are shown at the bottom of in Fig. $1 b$ - they are identical within the limits of experimental error. Opposed to this, significant differences were detected in the IR spectra of adsorbed CO (Fig. 2, spectra d, c, b): after the air treatment, the signal of the positively charged Au clusters $\mathrm{Au}_{\mathrm{n}}{ }^{\delta+}$ had almost completely vanished. In the STEM images, some changes are visible as well. The particles look more bulky and the disordered patches have practically disappeared (see, however, Fig. 3D3). These changes may be related to the destruction of the $\mathrm{Au}_{\mathrm{n}}^{\delta+}$ clusters. It has been recently shown by theoretical calculations that the charge on these entities arises from interactions with $\mathrm{O}$ vacancies on which they are anchored [18]. When these defects become oxidized by the Air_623K treatment, individual atoms are less stabilized by the support and join larger (neutral) aggregates, which nicely explains the changes observed. It may be interesting to study this aspect in more detail on a model $\mathrm{TiO}_{2}$ surface.

The data reported so far provide nice examples for the merits and shortcomings of each method in the present situation. With respect to XAFS, its unique contributions were based rather on the XANES than on the EXAFS part because none of the other methods was able to identify the actual oxidation state of gold in total: while IR detects only sites that adsorb the probe (which is an advantage from another point of view) and remains qualitative as long as 
extinction coefficients are unknown, electron microscopy is blind for oxidation states. EXAFS supported the conclusions on well-defined oxidation states by the absence of significant $\mathrm{Au}-$ $\mathrm{Au}^{0}$ scattering in the initial state and of Au-O scattering after thermal treatments. However, the information on the population of the coordination sphere, which is usually considered the strong point of EXAFS, proved to be rather prone to misinterpretation as revealed by the TEM images. The reasons are clear: being an averaging technique, EXAFS provides average particle sizes, but does not indicate the width of the size distribution unless the latter is very broad. Therefore, the presence of atomically dispersed Au and of (a few) large particles after He_623K escaped detection. In addition, the intensity of a shell depends on the uniformity of distances between absorber and neighboring atoms. Static disorder within the shell decreases its scattering intensity and may result in its disappearance as encountered in the initial sample. Despite concerns on statistical significance, electron microscopy is indispensable for any description of the morphology of samples. In our case, it saved from misinterpretation of XAFS data. However, after the recent advances in resolution, the question how to quantify the heterogeneity of samples has to be raised again. Except for the air-treated sample, the variety of shapes and sizes of Au clusters implies that one will have to go beyond simple particle size distributions. What was visualized by TEM as a rather homogeneous array of $2 \mathrm{~nm}$ particles (He_623 K, cf. Fig. S4 in [8]) was revealed by HAADF-STEM to also contain disordered patches and single atoms in a significant quantity (Fig. 3C2, C3, remaining micrographs in [8]). The decision if the disordered Au species should have been detected by IR and XAFS in case they are Au cations depends on their quantity, which is difficult to assess from the electron microscopic images. The observation that Air_623K almost completely eliminated the disordered species as well as the $\mathrm{CO} / \mathrm{Au}_{\mathrm{n}}{ }^{\delta+} \mathrm{IR}$ signal suggests, however, that both are correlated. Apparently, $\mathrm{Au}^{0}$ may occur in disordered structures, and according to [18], these species acquire a slightly positive charge by interaction with an oxygen vacancy of the $\mathrm{TiO}_{2}$ 
surface. We therefore propose to identify the disordered Au patches in the reduced catalysts with the $\mathrm{Au}_{\mathrm{n}}{ }^{\delta+}$ state.

IR with probe molecules has the unique potential to differentiate oxidation states of surface atoms, however, only as far as they adsorb the probe. The present case where the probe is the reactant as well is most favorable as it allowed us assigning $\mathrm{CO}$ oxidation detected at $90 \mathrm{~K}$ to the few $\mathrm{Au}^{3+}$ sites exposed in the initial state (Fig. 2a, spectrum a'). The CO probe was able to distinguish sites on neutral from sites on slightly charged $\mathrm{Au}^{0}$ clusters $\left(\mathrm{Au}_{\mathrm{n}}{ }^{0}\right.$ and $\left.\mathrm{Au}_{\mathrm{n}}{ }^{\delta+}\right)$. None of the other methods was able to detect $\mathrm{Au}_{\mathrm{n}}{ }^{\delta+}$, and it is very doubtful if XPS, which may have contributed some of the information provided by XAFS in our study, could discriminate $\mathrm{Au}^{0}$ and $\mathrm{Au}_{\mathrm{n}}{ }^{\delta+}$, in particular when coexisting. The problem of quantitative analysis remains with IR except for the few cases where extinction coefficients are known. In addition, the present example shows that independent information on the oxidation state of the element of interest may be very important, when the sample has to be pretreated to expose empty adsorption sites.

From the combination of the characterization data detailed here with data on CO conversion it was shown in ref. [8] that catalysis in the state after activation in the feed at $303 \mathrm{~K}$ ("COox") occurs on sites containing $\mathrm{Au}^{3+}$ as long as the temperature remains well below $273 \mathrm{~K}$. It could not be decided whether the $\mathrm{Au}^{3+}$ cations require the assistance of coexisting $\mathrm{Au}^{0}$ species for this, because it was impossible to compare the reactivity data in the flow system with the static data in the IR spectrometer at $90 \mathrm{~K}$ where $\mathrm{Au}^{3+}$ definitely operated on its own. In the 220-260 $\mathrm{K}$ range, where $\mathrm{CO}$ adsorption on $\mathrm{Au}^{3+}$ was proven by IR [8], cancellation of the adsorption enthalpy with the true activation energy lead to ranges of very low, even negative activation energies (conversion plateaus). At higher temperatures, where $\mathrm{Au}^{3+}$ can no longer bind $\mathrm{CO}$, the conversion increased again, now obviously supported by $\mathrm{Au}_{\mathrm{n}}{ }^{\delta+}$ sites. After He_623K, the conversion plateau disappeared, instead, usual S-shaped conversion curves 
were obtained [8], obviously arising from the $\mathrm{Au}_{\mathrm{n}}{ }^{\delta+}$ sites. After air_623K, both activity and $\mathrm{Au}_{\mathrm{n}}{ }^{\delta+} \mathrm{IR}$ signature were strongly decreased. One may wonder if the significant residual activity may be ascribed to the predominating neutral Au clusters. However, as the activation energy did not change [8] and $\mathrm{Au}_{\mathrm{n}}{ }^{\delta+}$ was not completely destroyed (Fig. 2b, spectrum d), we tend to relate the residual $\mathrm{CO}$ oxidation activity to the residual $\mathrm{Au}_{\mathrm{n}}{ }^{\delta+}$ sites.

\section{Conclusions}

Synthesis of $\mathrm{Au} / \mathrm{TiO}_{2}$ by deposition-precipitation of $\mathrm{HAuCl}_{4}$ with subsequent freeze drying resulted in patches of $\mathrm{Au}^{\mathrm{III}}$ oxo species ranging from isolated $\mathrm{Au}$ ions to three-dimensional clusters. Despite the aggregation, Au-Au scattering was not observed in EXAFS, obviously due to pronounced disorder. The gold adsorption sites were almost completely inaccessible to $\mathrm{CO}$, probably due to site blockage by residual water molecules. After applying the catalyst in $\mathrm{CO}$ oxidation at $\mathrm{T} \leq 303 \mathrm{~K}$, only a minority of the $\mathrm{Au}^{\mathrm{III}}$ species was reduced to $\mathrm{Au}^{0}$, which was identified in two states by IR spectroscopy of adsorbed CO: neutral and positively charged clusters $\left(\mathrm{Au}_{\mathrm{n}}{ }^{0}, \mathrm{Au}_{\mathrm{n}}{ }^{\delta+}\right)$, while the appearance of the catalyst in HAADF-STEM appeared unchanged except for few bulk metal particles. Thermal treatment in He at $623 \mathrm{~K}$ resulted in complete reduction of $\mathrm{Au}$,II, again with coexisting $\mathrm{Au}_{\mathrm{n}}{ }^{0}$ and $\mathrm{Au}_{\mathrm{n}}{ }^{\delta+}$, while microscopy revealed the survival of plenty of disordered structures, even single atoms, coexisting with 1-2 $\mathrm{nm}$ particles and few large crystallites. Calcination in air at $623 \mathrm{~K}$ almost completely eliminated the $\mathrm{Au}_{\mathrm{n}}^{\delta+}$ state and the disordered species, resulting in well-dispersed three-dimensional Au metal nanoparticles on the $\mathrm{TiO}_{2}$ surface. 


\section{Acknowledgements}

We gratefully acknowledge financial support by the German Science Foundation (DFG) in the frame of the Collaborative Research Center "Metal-substrate interactions in heterogeneous catalysis" (SFB 558). We thank station scientists of Hasylab (Desy, Hamburg) and Alba (Barcelona) for their engagement during the measurements, in particular Dr. K. V. Klementiev for his support during precomissioning beamtime.

(Wir bedanken uns bei der DFG für Förderung im Rahmen des SFB 558 „Metall-Substrat-Wechselwirkungen in der Heterogenen Katalyse“. Wir danken den Mitarbeitern von Hasylab (Hamburg) und Alba (Barcelona) für ihren Einsatz während den Strahlzeiten, insbesondere Dr. K. V. Klementiev für seine Unterstützung während einer Erprobungs-Strahlzeit an Alba.)

\section{Kurzzusammenfassung}

Der Artikel demonstriert das Zusammenspiel und die besonderen Beiträge dreier Charakterisierungstechniken (Röntgenabsorptionsspektroskopie, Elektronenmikroskopie, Tieftemperatur-IR-Spektroskopie von adsorbiertem CO) bei der Aufklärung der Speziesstruktur eins

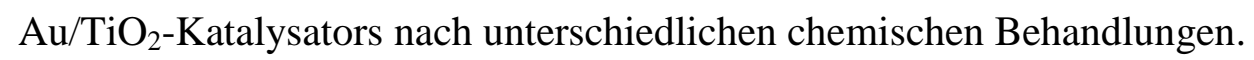

The paper demonstrates the interplay between three characterization techniques (X-Ray Absorption Spectroscopy, Electron Microscopy, Low-temperature IR Spectroscopy of adsorbed $\mathrm{CO}$ ) and their particular contributions during the elucidation of the species structure of a titania-supported gold catalysts after different chemical treatments. 


\section{References}

[1] A. Hellman, E. J. Baerends, M. Biczysko, T. Bligaard, C. H. Christensen, D. C. Clary, S. Dahl, R. van Harrevelt, K. Honkala, H. Jonsson, G. J. Kroes, M. Luppi, U. Manthe, J. K. Norskov, R. A. Olsen, J. Rossmeisl, E. Skulason, C. S. Tautermann, A. J. C. Varandas, J. K. Vincent, Journal of Physical Chemistry B 2006, 110, 17719.

[2] K. Honkala, A. Hellman, I. N. Remediakis, A. Logadottir, A. Carlsson, S. Dahl, C. H. Christensen, J. K. Norskov, Science 2005, 307, 555.

[3] R. Schlogl, Angewandte Chemie-International Edition 2003, 42, 2004.

[4] J. B. Hansen, P. E. H. Nielsen, in Handbook of Heterogeneous Catalysis, Vol. 6, 2nd ed. (Eds.: G. Ertl, H. Knözinger, F. Schüth, J. Weitkamp), Wiley-VCH, Weinheim, 2008, pp. 2920.

[5] M. Behrens, F. Studt, I. Kasatkin, S. Kuhl, M. Hävecker, F. Abild-Pedersen, S. Zander, F. Girgsdies, P. Kurr, B. L. Kniep, M. Tovar, R. W. Fischer, J. K. Norskov, R. Schlögl, Science 2012, 336, 893.

[6] C. Woell, M. Muhler, Phys. Stat. Solid. 2013, 250, 1069.

[7] B. M. Weckhuysen, American Scientific Publishers, Stevenson Ranch, California, 2004.

[8] W. Grünert, D. Großmann, H. Noei, M. M. Pohl, I. Sinev, A. De Toni, Y. Wang, M. Muhler, Angew. Chem. Int. Ed. 2014.

[9] K. V. Klementiev.

[10] Y. Wang, A. Glenz, M. Muhler, C. Wöll, Rev. Sci. Instrum. 2009, 80, 13108.

[11] M. W. E. van den Berg, A. De Toni, M. Bandyopadhyay, H. Gies, W. Grünert, Appl. Catal. A 2011, 391, 268.

[12] I. X. Green, W. J. Tang, M. Neurock, J. T. Yates, Science 2011, 333, 736.

[13] J. S. Lee, Z. Zhang, X. Y. Deng, D. C. Sorescu, C. Matranga, J. T. Yates, Journal of Physical Chemistry C 2011, 115, 4163.

[14] M. A. P. Dekkers, M. J. Lippits, B. E. Nieuwenhuys, Catalysis Letters 1998, 56, 195.

[15] F. Menegazzo, M. Manzoli, A. Chiorino, F. Boccuzzi, T. Tabakova, M. Signoretto, F. Pinna, N. Pernicone, Journal of Catalysis 2006, 237, 431.

[16] M. Y. Mihaylov, J. C. Fierro-Gonzalez, H. Knozinger, B. C. Gates, K. I. Hadjiivanov, Journal of Physical Chemistry B 2006, 110, 7695.

[17] M. Borovski, J. Phys. IV 1997, 7, C2.

[18] M. Farnesi Camellone, J. Zhao, L. Jin, Y. Wang, M. Muhler, D. Marx, Angewandte Chemie International Edition 2013, 52, 5780. 


\section{Legends}

Figure 1. $\mathrm{Au} \mathrm{L}_{\mathrm{III}} \mathrm{XAFS}$ spectra of the $\mathrm{Au} / \mathrm{TiO}_{2}$ catalyst in different states. a) near-edge structure (XANES), references for $\mathrm{Au}^{\mathrm{III}}\left(\mathrm{HAuCl}_{4}\right)$ and $\mathrm{Au}^{0}$ (Au foil) given vor comparison, "LC" labels result of linear combination analysis, b) extended X-ray absorption fine structure (EXAFS), with Au foil as reference. All spectra measured at $77 \mathrm{~K}$ except for those marked by *, which have been measured at room temperature.

Figure 2. UHV-FTIR spectra of $\mathrm{CO}$ adsorbed on $\mathrm{Au} / \mathrm{TiO}_{2}$ in different states. a) initial sample, after freeze drying, CO adsorption at $90 \mathrm{~K}$ and $1 * 10^{-4} \mathrm{mbar}$, a') as a, but evacuated at $110 \mathrm{~K}, \mathrm{a}_{500}$ ) as a, heated in vacuum to $500 \mathrm{~K}$, CO re-adsorbed at $90 \mathrm{~K}$ and $1 * 10^{-4}$ mbar, $\left.\mathrm{a}_{500}{ }^{\prime}\right)$ as $\mathrm{a}_{500}$, but evacuated at $155 \mathrm{~K}, \mathrm{~b}$ ) sample after interaction with feed at $303 \mathrm{~K}, \mathrm{CO}$ adsorption at $90 \mathrm{~K}$ and $5 * 10^{-4} \mathrm{mbar}$, b') as b, but evacuated at $170 \mathrm{~K}$, c) sample after thermal treatment in $\mathrm{He}$ at $623 \mathrm{~K}$, CO adsorption at $90 \mathrm{~K}$ and $5 * 10^{-4}$ mbar, c') as c, but evacuated at $130 \mathrm{~K}$, d) sample after thermal treatment in synthetic air at $623 \mathrm{~K}, \mathrm{CO}$ adsorption at $90 \mathrm{~K}$ and $5 *$ $10^{-4}$ mbar, d') as c, but evacuated at $130 \mathrm{~K}$.

Figure 3. HAADF-STEM images of the $\mathrm{Au} / \mathrm{TiO}_{2}$ catalyst (A) in the initial state, (B) after catalysis at $\mathrm{T} \leq 303 \mathrm{~K},(\mathrm{C})$ after thermal treatment in He at $623 \mathrm{~K}$, and (D) thermal treatment in synthetic air at $623 \mathrm{~K}$. Some individual atoms are encircled. 

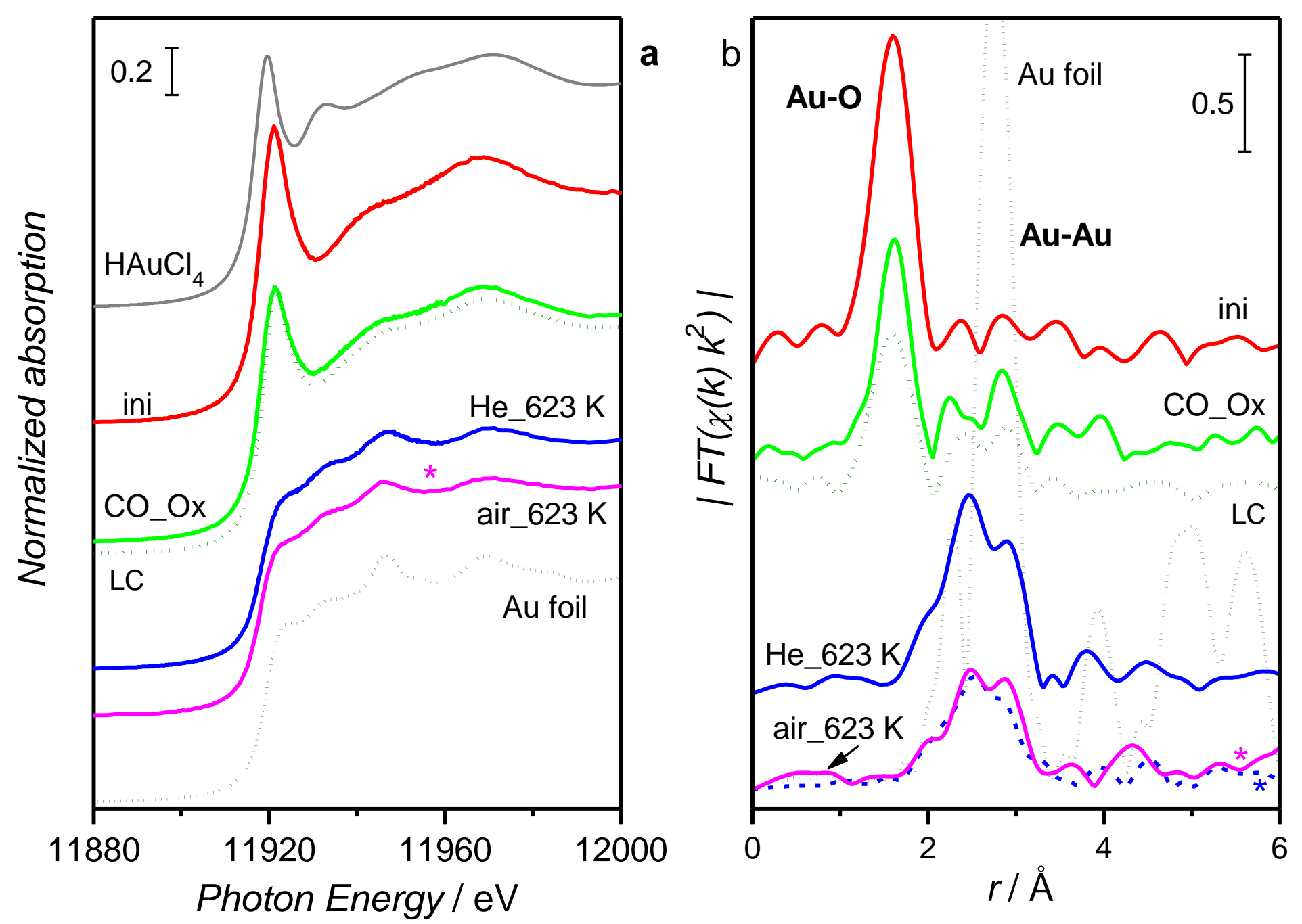

Figure 1 

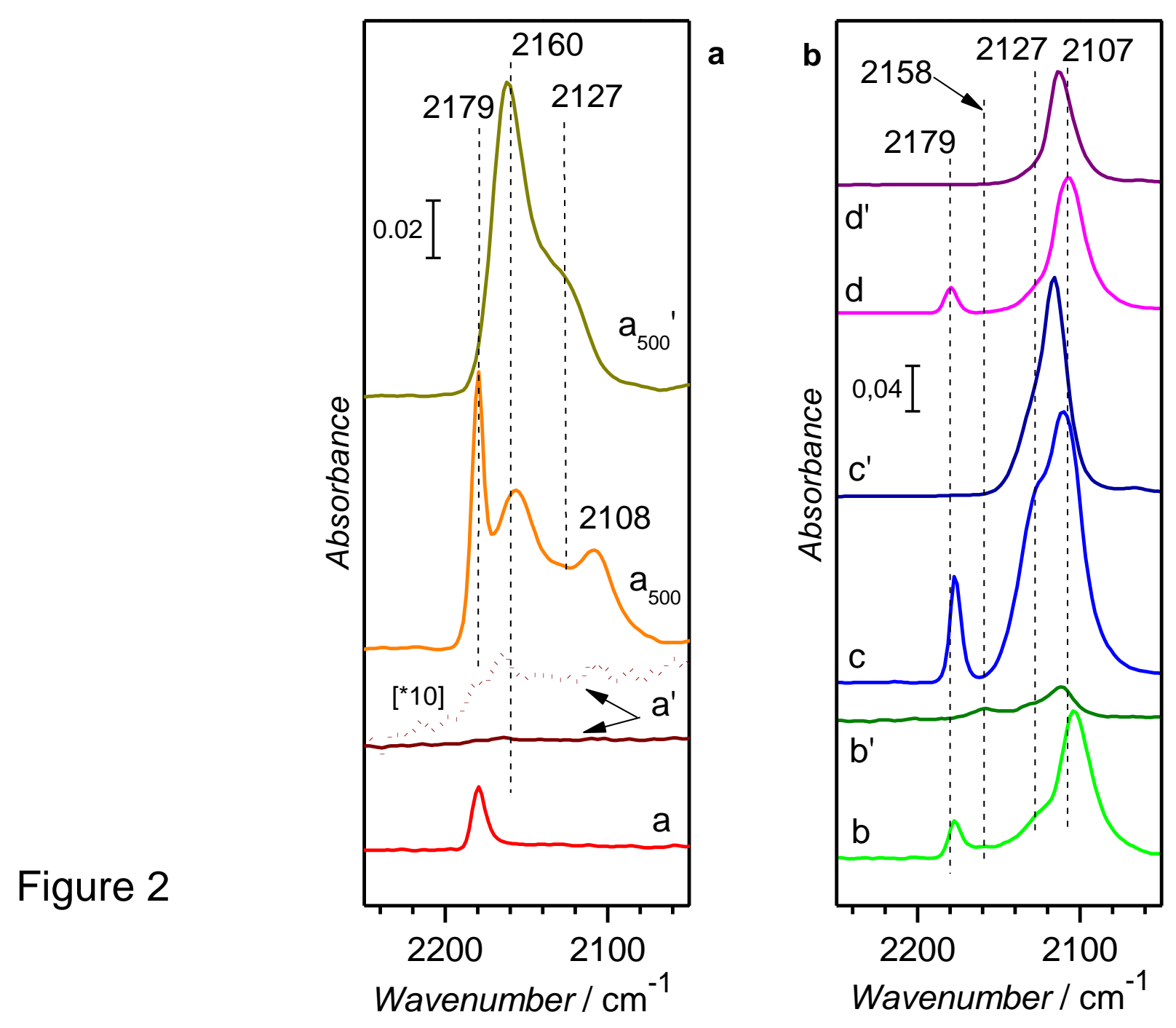


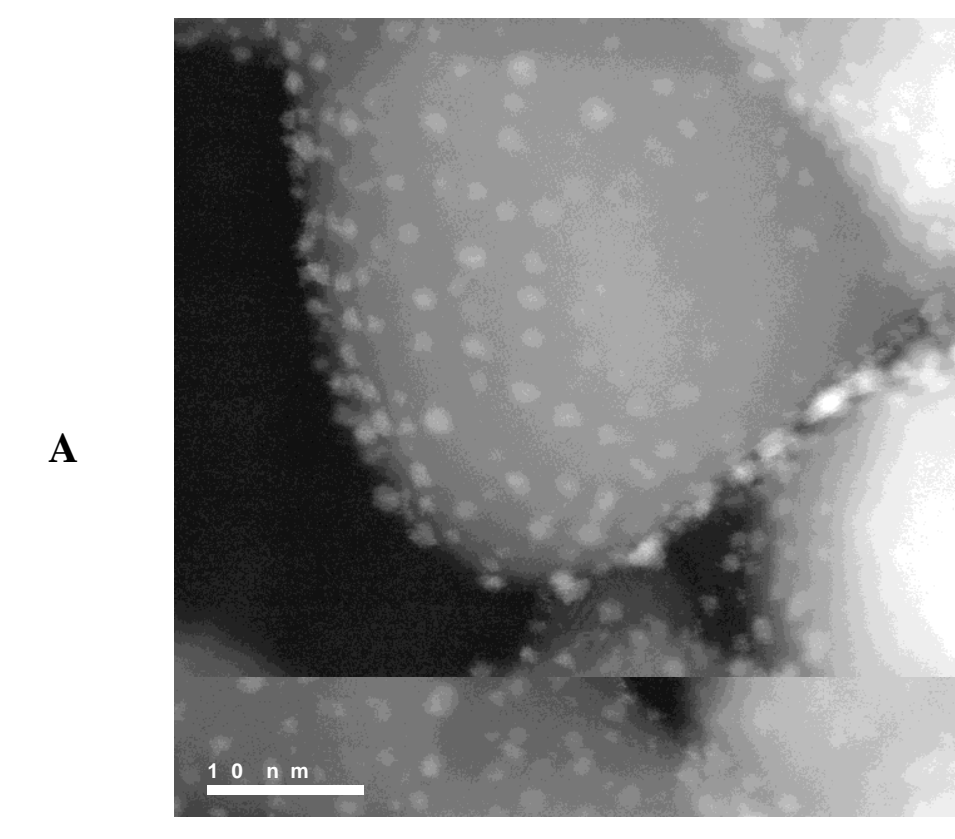

1

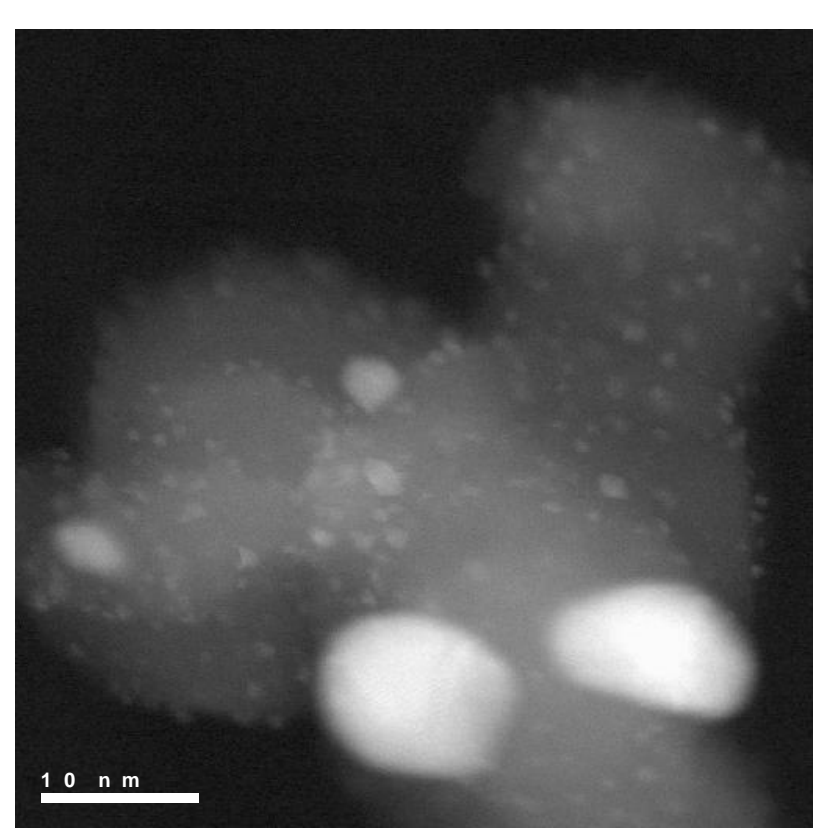

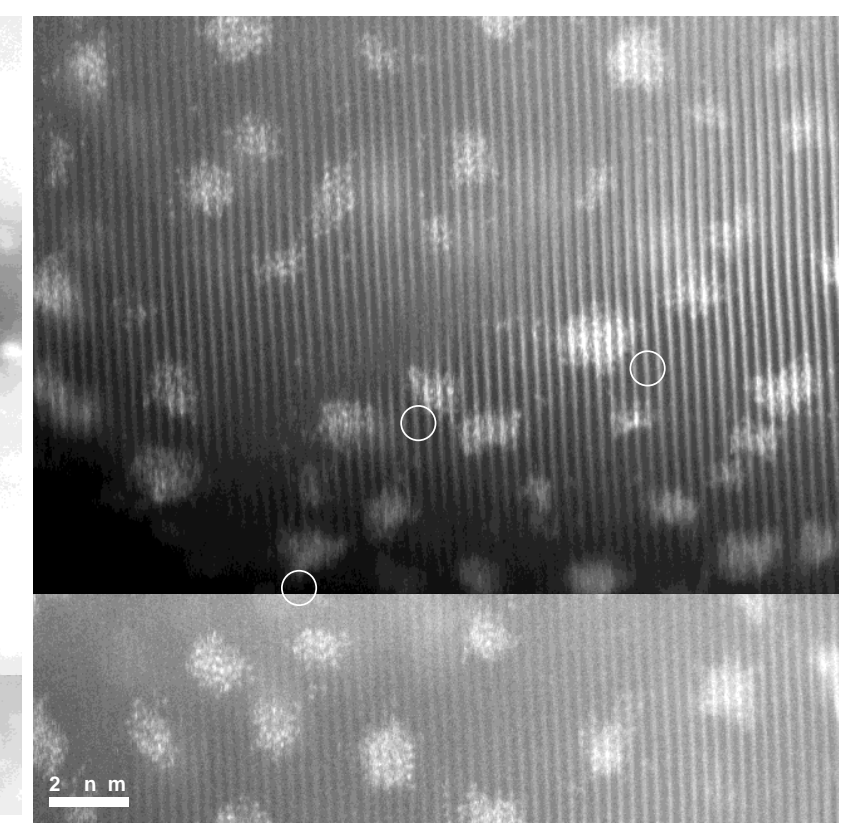

2

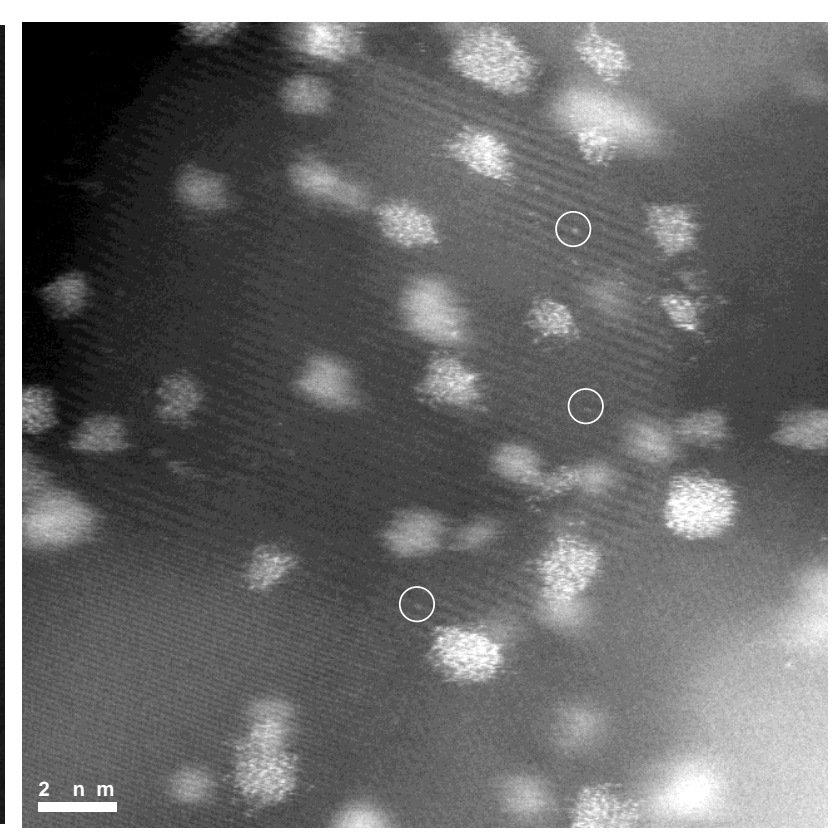

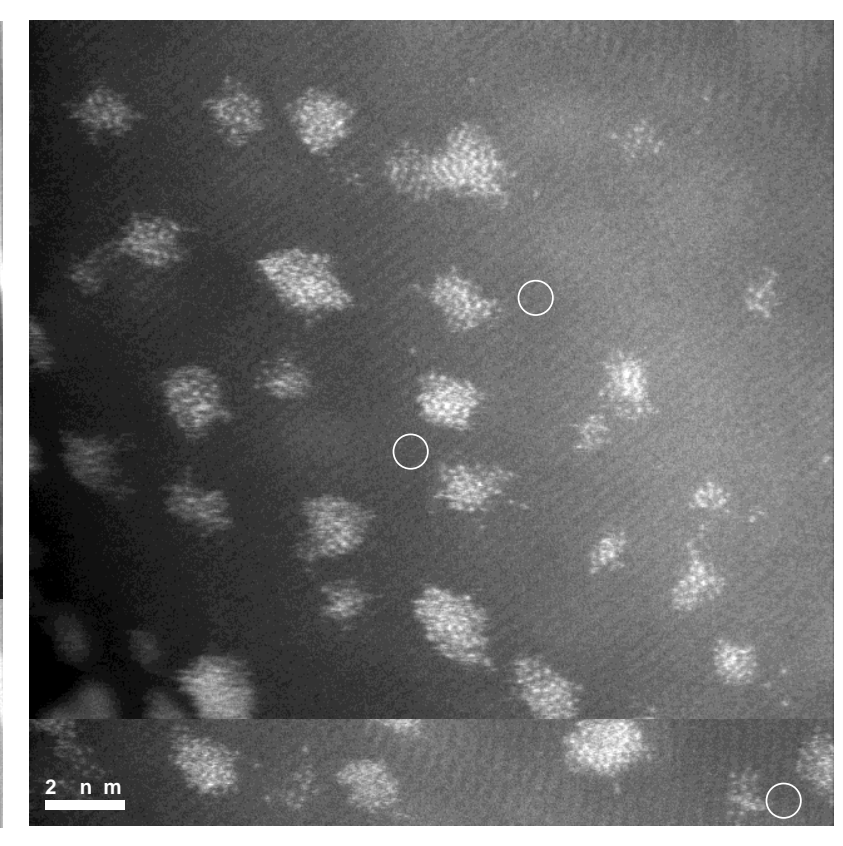

3

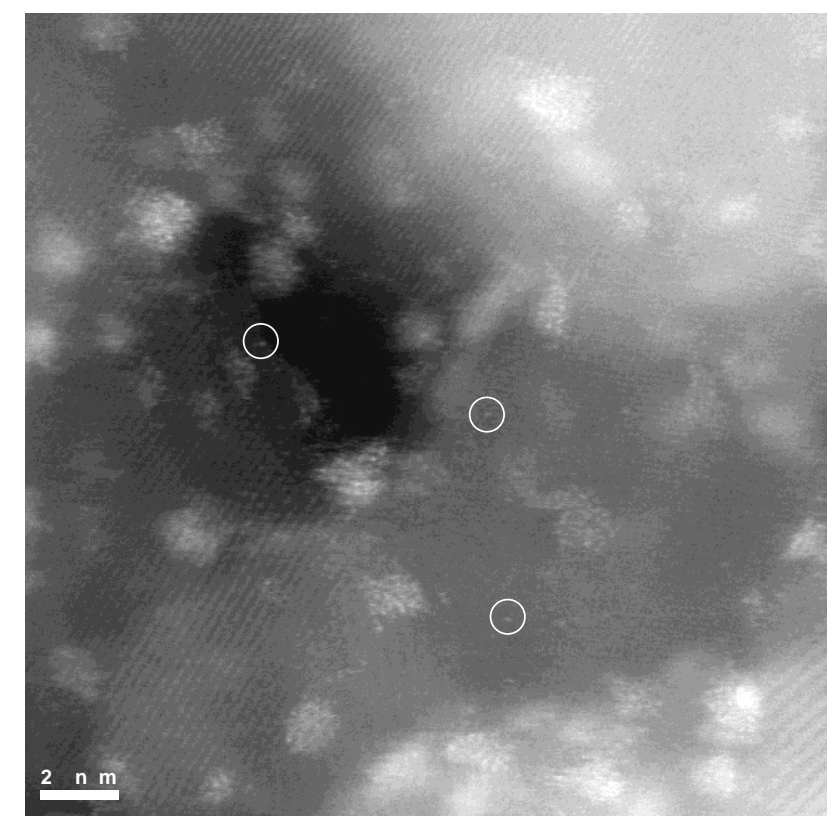




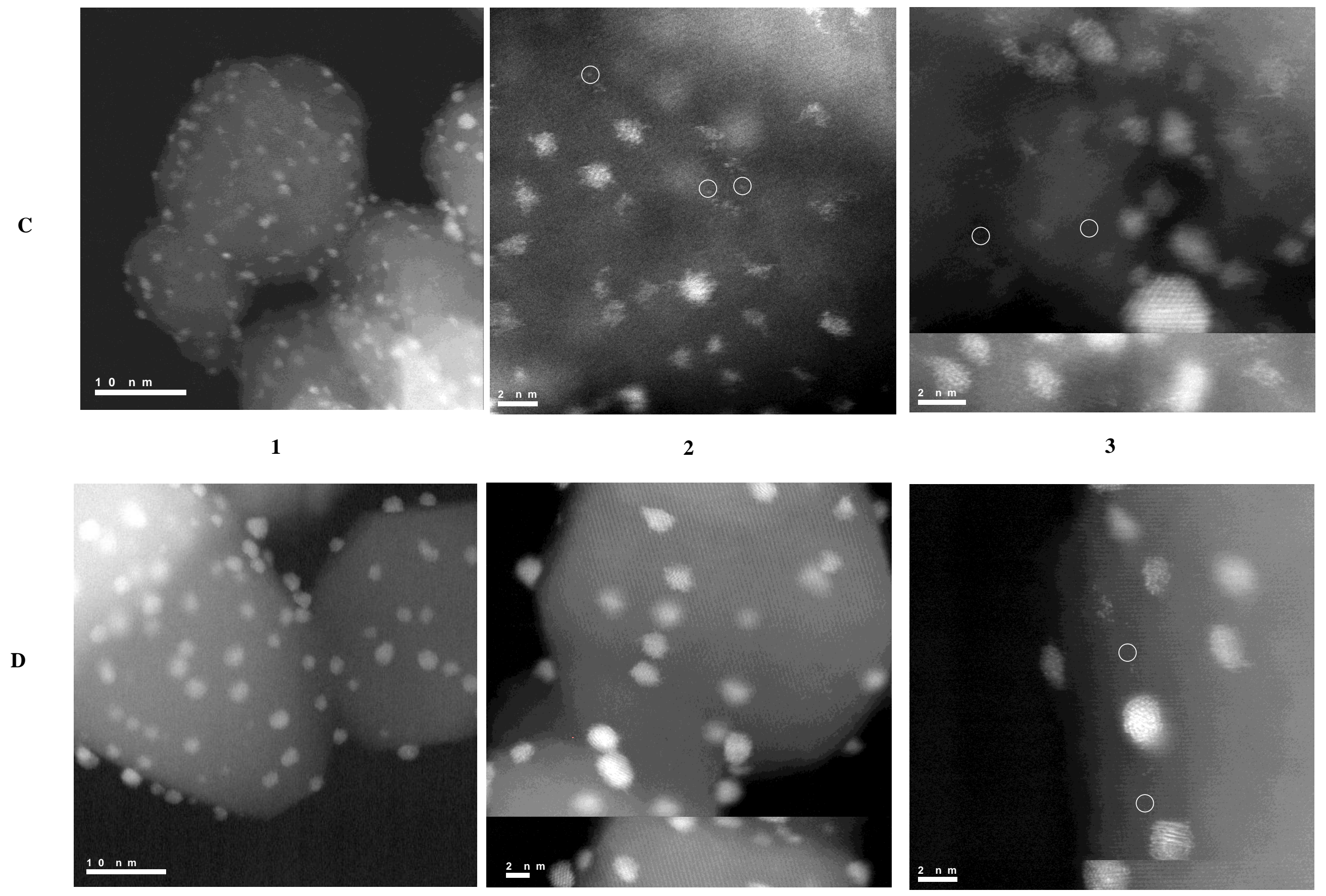

